University of New Hampshire

University of New Hampshire Scholars' Repository

Faculty Publications

$10-1-2021$

\title{
Teaching with Quantitative Data in the Social Sciences at the University of New Hampshire: An Ithaka S+R Local Report
}

\author{
Patricia Condon \\ University of New Hampshire, Durham, patricia.condon@unh.edu \\ Eleta Exline \\ University of New Hampshire, Durham, eleta.exline@unh.edu \\ Louise Buckley \\ University of New Hampshire, Durham, louise.buckley@unh.edu
}

Follow this and additional works at: https://scholars.unh.edu/faculty_pubs

Part of the Curriculum and Instruction Commons, Library and Information Science Commons, and the Scholarship of Teaching and Learning Commons

\section{Recommended Citation}

Condon, P.B., Exline, E., \& Buckley, L.A. (2021). Teaching with Quantitative Data in the Social Sciences at the University of New Hampshire: An Ithaka S+R Local Report. https://dx.doi.org/10.34051/p/2021.39

This Report is brought to you for free and open access by University of New Hampshire Scholars' Repository. It has been accepted for inclusion in Faculty Publications by an authorized administrator of University of New Hampshire Scholars' Repository. For more information, please contact Scholarly.Communication@unh.edu. 


\title{
University of New Hampshire
}

Library

\section{Teaching with Quantitative Data in the Social Sciences at the University of New Hampshire}

\author{
An Ithaka S+R Local Report
}

October 1, 2021

Patricia B. Condon, Assistant Professor, Research Data Services Librarian, University of New Hampshire, Durham

Eleta Exline, Associate Professor, Scholarly Communication Librarian, University of New Hampshire, Durham

Louise A. Buckley, Associate Professor, Social Sciences, Public Policy \& Government Information Librarian, University of New Hampshire, Durham

Recommended Citation: Condon, P.B., Exline, E., \& Buckley, L.A. (2021). Teaching with Quantitative Data in the Social Sciences at the University of New Hampshire: An Ithaka S+R Local Report.

https://dx.doi.org/10.34051/p/2021.39

Funding for this project was provided by the UNH Library.

The researchers extend a sincere thank you to the study participants, each of whom was generous with their time and thoughtful remarks. 


\section{Executive Summary}

\section{Teaching with Quantitative Data in the Social Sciences at the University of New Hampshire: An Ithaka S+R Local Report}

October 1, 2021

Patricia B. Condon (patricia.condon@unh.edu)

Eleta Exline (eleta.exline@unh.edu)

Louise A. Buckley (louise.buckley@unh.edu)

\section{Introduction}

The University of New Hampshire (UNH) Library conducted an exploratory study of the pedagogical practices of social science instructors at UNH who teach using quantitative data in undergraduate courses. This study is connected to a suite of parallel studies being developed locally at other higher education institutions and coordinated by Ithaka S+R.

The aims of this study were to

- explore the ways in which instructors teach and engage undergraduates in the social sciences using quantitative data;

- understand the support needs of these instructors;

- develop actionable recommendations for campus stakeholders; and

- identify opportunities for the development of resources, services, or activities in the library to support the use of quantitative data in the classroom.

For the UNH study, the research team recruited eleven participants through convenience sampling for one-on-one, semi-structured interviews. The study sample included lecturers, assistant professors, associate professors, and full professors across seven social science disciplines from the Durham and Manchester campuses.

\section{Findings}

Courses using data provide a unique opportunity for students to gain experience by working with hands-on examples. The two overarching themes identified speak to the motivations of instructors who teach with data and the challenges and opportunities they face.

- Teaching with data for data literacy and scientific literacy This theme centers on introducing or strengthening a broad set of foundational skills students need to be successful. These include a wide range of competencies connected to critical thinking, from essential information and data literacies to understanding scientific methodologies. 
- Teaching with data for statistical, data, and tools skill building

This theme focuses on working with datasets and the development of skills such as understanding statistical concepts, variables and measurements, and tools for working with data. Also emphasized are barriers faced by students and strategies instructors employ to help students overcome those barriers.

\section{Recommendations}

Based on the findings, the research team proposes the following initial recommendations, which include collaborative actions that campus stakeholders can take to better support social science instructors teaching with data.

Recommendation 1: Provide support for instructors in locating and sharing data for teaching

Recommendation 2: Provide support for students who need extra help with math and statistics

Recommendation 3: Provide enhanced software support for both students and instructors

Recommendation 4: Provide learning opportunities for instructors on teaching with data, student skills retention, and new research methodologies and data analysis and visualization practices

Recommendation 5: Enhance library support for teaching with data and foster partnerships with campus stakeholders to explore recommendations 1-4

\section{Conclusion}

Data literacy is an important set of competencies in part because of the quality and quantity of data students encounter; they need to have the ability to critically evaluate data, methods, and claims. This study directed attention to an area that had not previously been focused on at UNH and is an important first step toward creating greater awareness and community of practice for social science instructors teaching with data. Investigating questions about teaching undergraduate students to work with data was illuminating to the participants and the research team. The UNH Library offers research data services and is exploring new ways of supporting data literacy. UNH has opportunities to create additional supports for instructors and students that could improve student learning outcomes. Such efforts may require cross-college or crossdepartment coordination as well as administrative support.

To download full report: https://dx.doi.org/10.34051/p/2021.39 


\section{Table of Contents}

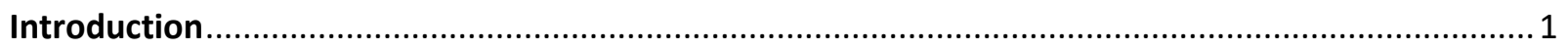

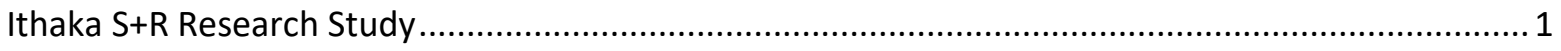

Social Sciences at the University of New Hampshire ..................................................................... 1

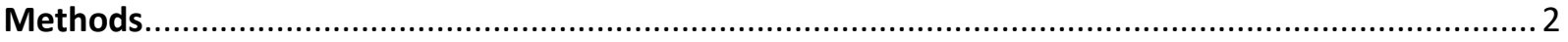

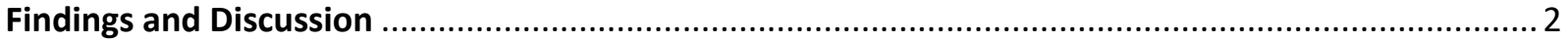

Teaching with Data for Data and Scientific Literacies................................................................. 2

Teaching with Data for Statistical, Data, and Tools Skill Building ................................................. 4

COVID-19 Challenges and Opportunities for Teaching with Data ..................................................... 7

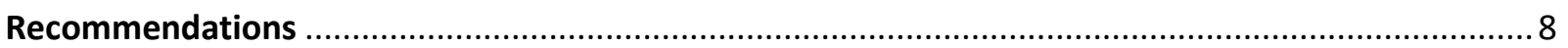

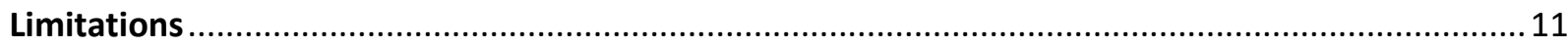

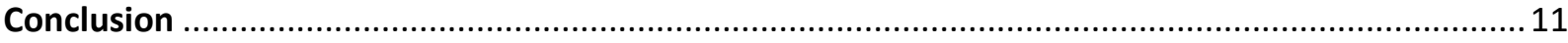

References …

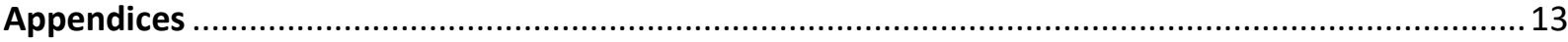

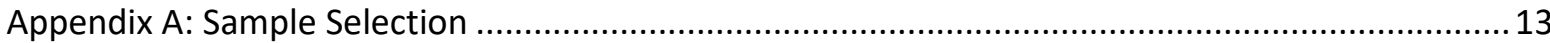

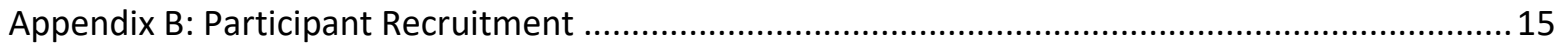

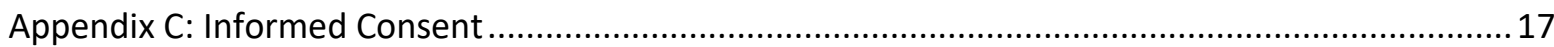

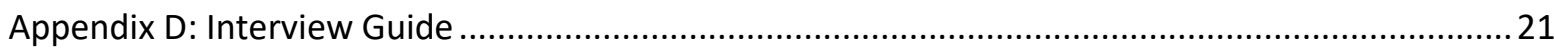

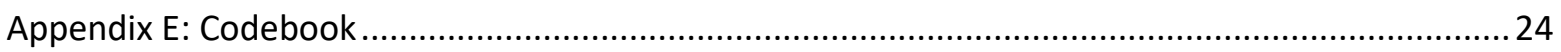

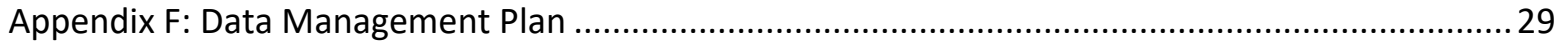

Appendix G: Additional Comments on Useful Training and Assistance ............................................30

Appendix H: Library Support for Data-Related Activities at UNH ................................................. 32 


\section{Introduction}

The University of New Hampshire (UNH) Library conducted an exploratory study of the pedagogical practices of social science instructors at UNH who teach using quantitative data in undergraduate courses. The goal of the study was to better understand instructors' undergraduate teaching practices related to the use of quantitative data for meeting course learning objectives. As the UNH Library continues to develop their data services program including support for data literacy, understanding the local practices and needs of the social science instructors can help in making more informed decisions about services. Additionally, this study will help inform campus stakeholders (such as Academic Technology, Center for Excellence and Innovation in Teaching \& Learning, and college deans and department chairs) of potential opportunities.

The aims of this study were to

- explore the ways in which instructors teach and engage undergraduates in the social sciences using quantitative data;

- understand the support needs of these instructors;

- develop actionable recommendations for campus stakeholders; and

- identify opportunities for the development of resources, services, or activities in the library to support the use of quantitative data in the classroom.

Two overarching themes emerged from the interview data that spoke to the motivations of instructors for teaching with data and the challenges and opportunities they face:

- teaching with data for data and scientific literacies

- teaching with data for statistical, data, and tools skill building

\section{Ithaka S+R Research Study}

The study undertaken at UNH is connected to a suite of parallel studies being developed locally at other higher education institutions. Ithaka $S+R$, a not-for-profit research and consulting organization that helps the academic, cultural, and publishing communities, was contracted to coordinate this multi-institutional effort and to provide guidance on research methodology and data analysis. In this report, we summarize the findings from the study conducted at UNH and provide recommendations based on those findings. Reports from the other institutions as well as the aggregate report developed by Ithaka $\mathrm{S}+\mathrm{R}$ are available separately.

\section{Social Sciences at the University of New Hampshire}

UNH is a medium-sized flagship Land, Sea, and Space Grant research university that was established as an agricultural and mechanical arts school in 1866. UNH enrolls around 15,000 students, with approximately 12,000 undergraduates and 3,000 graduate students across three 
campuses: Durham, Manchester, and the UNH Franklin Pierce School of Law in Concord. The College of Liberal Arts (COLA) on the Durham campus houses most of the social science disciplines; however, there are social science disciplines represented in all of the other colleges and on the Manchester campus. COLA has the largest enrollment of undergraduates with over 3,000 enrolled in spring of 2021. A list of disciplines in scope for this study can be found in Appendix A.

\section{Methods}

For the UNH local study, we recruited eleven participants through convenience sampling to participate in one-on-one, semi-structured interviews. We conducted recorded interviews online via Zoom, a video-conference software, during the fall of 2020. The study sample included lecturers, assistant professors, associate professors, and full professors across seven social science disciplines on two campuses.

After the interviews were transcribed and de-identified, we conducted qualitative coding of the transcripts based on grounded theory methodology (Strauss and Corbin, 2014). Coding and analysis were an iterative process. First, we each open coded the same three interviews to identify emergent patterns in the data. From there, we discussed and aligned our codes from the open coding and determined a final set of codes to use for analyzing the interviews. We then coded all the interview transcripts using this final set of codes.

For more details about the methodology and analysis, including sample selection, recruitment process, informed consent, the interview instrument, the codebook, and the data management plan, please see Appendices A-F.

\section{Findings and Discussion}

From the final set of codes, the themes that emerged directly address the first two aims of our study: explore the ways in which instructors teach and engage undergraduates in the social sciences using quantitative data and understand the support needs of these instructors. In addition to discussing these two themes below, we explore the comments that participants made related to challenges and opportunities that instructors faced during the shift to online teaching during the COVID-19 pandemic.

\section{Teaching with Data for Data and Scientific Literacies}

The first theme that emerged from the interviews is a desire among participants to introduce or strengthen a broad set of foundational skills they believe students need to be successful. These skills include a wide range of competencies connected to critical thinking, from essential information and data literacies to understanding scientific methodologies and their underpinnings. Courses using data provide a unique opportunity for students to gain experience with these topics by working with hands-on examples.

Although data, information, and scientific literacy skills development are not always explicit learning objectives in courses using data, they are addressed by most participants because of their importance as life skills and as foundations for more explicit learning objectives 
around scientific thinking and disciplinary research methods. Participants share a collective sense of duty toward addressing what they perceive as insufficiencies in these skills for both pragmatic and idealistic reasons: students both need these skills for coursework and should have these skills for life beyond college. When participants emphasize learning information and data literacies among their implicit goals for a course, this is often expressed as helping students to "be savvier consumers" of data of all kinds. As savvy consumers of data, students need to be equipped to assess the validity of claims, and to be able to recognize misleading or false claims, whether those claims are intentionally deceptive, based on faulty reasoning, or due to poor methodology. Conversely, students should be able to recognize sound methodology where the arguments and conclusions presented are supported by the data cited.

\section{Data literacy}

One driver for including information and data literacies as course objectives is the shared perception among participants that there is a flood of low-quality online representations of data and that much of what students will encounter in their everyday lives is, as one participant bluntly stated, "complete garbage." Advertising, political messaging, and the proliferation of both via social media play a role in what students are exposed to regularly, and some students lack the academic or life experience to make sense of conflicting information. As one participant mentions, "depending on where they're coming from in life, [students] may or may not have had any life experience to really give them a foundation to think about data from." There is a sense of urgency around helping students navigate the challenges of an information environment in which accuracy is sometimes secondary to messaging and "the difference between opinion and argument" can be difficult to discern. Students need to know enough about data to begin to ask interrogative questions, identify biases, and recognize misrepresentations:

Are there other data sources that might tell a different story? Or is there something about the way this data is being presented that biases the presentation toward a certain type of conclusion? ...I want them to ask those kinds of questions of me. And then, also, of themselves, as they work with data. Because we're being bombarded all the time with information, and oftentimes with just conclusions and statements about this is the way things are.

Data literate students should be equipped to question the data and claims they encounter and to understand that data "doesn't tell a story by itself," but is interpreted, analyzed, and presented by people. They also need a level of data proficiency to progress to more advanced courses, to be members of the workforce in which those skills are increasingly important, and to be "a good citizen" in a participatory democracy in which even accurately presented data can be used to tell conflicting stories.

Students who come to a course with some exposure to data concepts are unlikely to have uniform knowledge, presenting some teaching challenges to instructors who must meet students where they are while still focusing on specific course content. Some students will have personal experience that will help them connect to data concepts in meaningful ways. Having a medical issue, for example, might encourage a student to think more about the meaning of 
public health data, serving as something of an anchor in that student's own life. Students from Engineering or Computer Science programs tend to do well with data concepts because they have prior experience with software, written analysis, or computer languages. This diversity of experience results in what one participant described as a "heterogeneous knowledge base" within a single course that makes teaching course content at the appropriate level more difficult.

\section{Scientific literacy}

Many courses using data have explicit learning objectives to introduce students to disciplinary research methods. Students transition from information and data literacies as academic and life skills to contextualizing these literacies in an understanding of the scientific method and social science disciplinary research methodologies, setting the stage for deeper learning about methods and knowledge building. To this end, participants use data as a tool to help acclimate students to scientific thinking:

It's a very important part of the process of helping students understand what scientists do, and what people who are real researchers do...really, it's really emphasizing the use of data and empirical knowledge to make sense of what we see.

The scientific method and its core principle of using empirical evidence to substantiate arguments is a different way of learning about the world than students may have encountered previously. It may even bump against other ways of learning that students have internalized, such as those with an arts and humanities focus where "the whole scientific method is sort of not their ballpark" and they may have developed a "pattern of learning" that works against their interpretation of numeric data, presumably a pattern based on textual rather than numeric analysis. Additionally, popular notions on how to conduct research, such as participation in informal polls and surveys, may cloud students' understanding of methods: "they've grown up in a world, unfortunately, where every fool with a modem and internet connection does what they call a survey, there is so much misperception about how to do survey research. I think that's really damaging."

Participants see social science courses, especially those taken by non-major students enrolled in a course to satisfy degree requirements, as an opportunity to make science concepts accessible to those who may not otherwise have such exposure. It is also a chance to dispel some of the mistrust of science that students may have developed by counteracting the idea that one can "say anything with numbers" and to introduce ideas about the ethical conduct of research.

\section{Teaching with Data for Statistical, Data, and Tools Skill Building}

While the previous section focused on contextualizing motivations for teaching with data in terms of holistic understanding of data, information, and scientific literacies, this section focuses on working with datasets and the development of skills such as understanding statistical concepts, variables and measurements, and tools for working with data. Participants expressed working with data as a continuum of concepts and skills that build upon one another. Understanding these complementary skills for working with data are explicit learning objectives 
for the courses that use data in teaching. Students tend to move from basic understanding of variables, how variables are measured and how data is structured, to interpreting graphic visualizations of data and conducting and interpreting statistical analyses, and finally to providing a written interpretation of findings and their significance. In some cases, software serves a pedagogical role in helping students practice analytical concepts; in other cases, participants consider working knowledge of software packages as transferable job skills. Depending on the learning objectives and content of a course, participants concentrate on different combinations of these analytical, conceptual, and technical skills.

\section{Challenges working with data}

The participants emphasized the challenges that students face when working with data. Students struggle for a variety of reasons, including difficulty with or anxiety around math skills, lack of experience with or lack of retention of math or statistical concepts, or obstacles learning to use analysis software. Problems specific to data concepts, such as understanding how variables are categorized, manipulated, and visualized, compound the issue. As noted by one participant, "I always have to try to remember how unfamiliar they are with using data." Concepts about datasets described as challenging by participants included levels of measurement (what the values are and how the data has been measured), understanding/visualization of rows and columns, and orienting oneself within the spreadsheet landscape. Students who face obstacles learning statistical analysis software used in courses, have trouble with basic computing tasks, or encounter issues with connectivity from home for remote work experience additional barriers to learning.

A common theme from participants was about math anxiety or difficulty with math skills:

So, technical challenges is [sic] one aspect, obviously, of it. I feel like, depending on their comfort level with Statistics, depending on their comfort level with math and with numbers, there's a level of anxiety that goes with it. That, they see a lot of numbers and just freak out.

Prior experiences around learning math in K-12 can lead students in some cases to develop a mindset that they are not going to be good at math or science. Some participants connected this mindset to internalized gender stereotypes about mathematics, i.e., that women are not as capable as men at working with numbers. It is each student's "own math ability, understanding, and their comfort level with numbers that plays a role" and participants viewed math anxiety as a barrier for students to overcome to gain a positive outcome that will be helpful after graduation. Participants described students as being capable of working with mathematical concepts, statistics, and data but needing to overcome the mindset of not being able to.

\section{Learning retention}

Carryover of learning from one course to another and retention of knowledge by students was described by participants as inconsistent as it pertained to basic statistics and/or a specific software. This led some participants to question both the variability of how concepts and software might be taught in different courses and how much students absorbed from one 
course to bring to the next course. One participant's observation, which was echoed by others, was that "there's too much variability in how that's being taught...so, I can't assume that they have anything...the retention of...information is not great."

Lack of retention can impact scaffolding learning objectives. For example, among the most important objectives participants have for their students is the analysis of data and interpretation and application of findings. Students whose grasp of data concepts is tentative struggle with these higher-level tasks. One participant explained:

Can you devise a provisional answer to that question, based on the data, and can you ground your conclusions in the evidence? I think that's a really important thing for them to understand... So that then, when they are exposed to more sophisticated techniques, that the kind of logic of data analysis is something that they're not trying to just get their head around for the first time.

\section{Locating and providing data for use}

In turn, providing data for students allows them to focus on specific skills or learning outcomes. If the learning objectives for the course do not include data collection or data processing, then including those activities distracts students from concentrating on data analysis and interpretation of findings. As one participant explained:

I ...bring them data that's already cleaned...It makes it a lot easier...Then they can start to get into what the story is with the data, rather than thinking about, ...what do you mean there are missing cases? ...I think [those higher-order concerns] just throw them for a loop.

While providing data required participants to spend time locating and preparing data prior to the start of the course, it saved time for the students. Among our participants, it was most common to find students engaging in data collection/acquisition and data processing in research methods courses or courses concerning the scientific process. In some courses, locating data from instructor-vetted sources was required. But in courses where students collected or located their own data for use, those skills were tied to course learning objectives.

\section{Support outside the classroom}

To address challenges faced by students who struggle with math, statistical software, and understanding data, participants noted limited support available outside the classroom. The most common support participants mentioned that was available for their students were graduate assistants, teaching assistants, and lab instructors. Many participants expressed that they are "lucky enough to have a grad research assistant" as additional support for their courses, someone who could provide one-on-one attention to students who need extra help. Most participants were unaware of other resources that their students might use outside of those that the instructor or course provided. Although participants mentioned video tutorials as options, they warned against advanced tutorials (such as those from software vendors) that provide more detail than students require and likely only lead to further frustration and confusion. 
There was a strong thread throughout many of the interviews associated with students learning to work with datasets and engage with data, information, and scientific literacies through application of concepts that speaks to instructors' motivations for teaching with data. This aligns with a comment made by one participant about the difference between understanding due to reading or listening and the deeper comprehension resulting from the actual experience of doing and actual practicing. Interestingly, it also characterized how participants described their own continued skills development related to learning new research methodologies, data analysis tools and techniques, and teaching practices for using data. Few participants have had formal training in teaching with data or research methods beyond their graduate training and have learned new things by experimentation or from peers. This highlights an opportunity for professional development related to teaching with data and also highlights the prominence that graduate training plays in learning research methods, data analysis, and pedagogical practices.

\section{COVID-19 Challenges and Opportunities for Teaching with Data}

As with other academic institutions, the sudden and unexpected pivot from in-person classes to virtual classes at UNH due to the COVID-19 pandemic disrupted the spring 2020 semester and caused reconsideration of course pedagogy for the fall semester, where many courses remained virtual while others were planned as hybrid. Even in-person classes had to be able to support students unable to come to class for extended periods due to quarantine, isolation, or other concerns. Several participants spoke specifically about impacts that the COVID-19 online teaching/remote learning environment had on courses that are typically designed to be taught face to face.

Participants made general observations about adaptations in their teaching for remote learning during the COVID-19 pandemic, but also discussed several changes when teaching with data. While it is demanding enough under typical circumstances to teach or troubleshoot when working with datasets or with analytical software, one participant mentioned that, in some cases, remote learning conditions made it more challenging to teach complex data analysis topics, which would, pre-COVID-19, have been demonstrated and followed along with synchronously in a classroom, allowing the instructor to see how students were faring and provide follow-up assistance or further instruction. A different participant commented that communication with students was at times less efficient: "Something that I can clear up in 30 seconds via conversation will take a dozen emails going back and forth." Yet another participant noted challenges with human subjects data such as lack of access to human subjects from whom students could collect data and ethical concerns involved in the possible showing of clips of human subjects during recorded Zoom lectures.

While the COVID-19 pandemic and response to the pandemic more frequently raised challenges, some positives were noted including increased availability of webinars for professional development and increased exchanges on community-sharing platforms about teaching, such as Pandemic Pedagogy on Facebook. Some also saw the pandemic as providing a further push toward adoption of Open Educational Resources in an effort to tailor course materials and reduce at least some financial and access concerns for students now dealing with 
other additional and unexpected changes in all aspects of their lives. COVID-19 also provided a setting for demonstration and discussion of data about health disparities, for example. Given that most participants teaching with data use real-life examples to demonstrate the value of good data analysis, being able to use current and ongoing events is especially relevant and engaging.

While most institutions of higher education are planning for "regular" in-person schedules for fall 2021, some of the modifications and adaptations resulting from the COVID-19 disruptions are likely to continue and perhaps even help accelerate changes and trends that were already underway pre-COVID-19 or present open questions for the coming academic year. Some of those developments that may affect teaching with data include possible loss of learning; potential increased interest or demand by students for online or hybrid access; continuing commitment to improving teaching, including retaining for face-to-face classes the effective techniques, approaches, and technologies learned and used for online learning; and redefining student engagement and student assessment (Alexander, 2021; Supiano, 2021; Cowell, 2021). No matter how these trends develop, it is clear that hybrid learning environments and their inherent challenges and opportunities will persist in the undergraduate classroom, and those teaching with data will have their own particular set of adaptations to meet the needs of data-informed learning.

\section{Recommendations}

Based on the findings, we propose five initial recommendations for local stakeholders. In many cases, these are opportunities for stakeholders to collaborate or partner with one other and/or with the library. Some of these recommendations build on the support already provided by the library and other units on campus. These recommendations address the last two aims of our study: develop actionable recommendations for campus stakeholders and identify opportunities for the development of resources, services, or activities in the library to support the use of quantitative data in the classroom. Additional details involving training and assistance suggestions from participants are described in Appendix G.

The following recommendations include collaborative actions that campus stakeholders can take to better support social science instructors teaching with data.

\section{Recommendation 1: Provide support for instructors in locating and sharing data for teaching.}

The findings suggest that instructors often provide datasets for students to analyze so that specific data literacy skills can be targeted. Identifying, locating, and cleaning datasets that are appropriate for class use can be time consuming. There are several resources available that cater to teaching with data and a variety of ways to support collecting and sharing datasets for instruction.

Some potential actions for supporting this recommendation include:

- Provide a centralized method for assembling and sharing data resources for instruction; for example, an online guide with a list of data sources crowd-sourced from social sciences instructors. 
- Promote increased use of ICPSR (Inter-university Consortium for Political and Social Research) teaching resources, (the library currently funds the university's membership in ICPSR). Investigate other teaching-with-data modules such as Social Science Data Analysis Network, and explore subscriptions for other resources such as SAGE Research Methods Datasets.

\section{Recommendation 2: Provide support for students who need extra help with math and statistics.}

The findings suggest that instructors have some concern about the math skills and retention of their students and that this has the potential to interfere with understanding data concepts and statistical analysis concepts. Some courses led by our participants had graduate assistants, who can provide some additional support to students and while UNH does have a Mathematics Center, that tutoring center is focused on supporting students taking one of several math courses. However, there is no general tutoring for math or specific support that caters to students working with math or statistics in social science contexts.

Some potential actions for supporting this recommendation include:

- Provide a centralized hub for collecting online resources and tutorials that target specific skills identified by instructors. There are quality resources already available through Khan Academy or on YouTube, but some tutorials can also be created to target specific course content.

- Develop a broadly accessible tutoring service for math, statistics, and data help for the social sciences and humanities students (and students in other fields) similar to the Writing Center.

\section{Recommendation 3: Offer enhanced software support for both students and instructors.}

Our findings suggest that instructors often teach students to use tools and software to work with data. Sometimes developing proficiency with the tool is a learning objective; other times the tool supports the learning objectives. Decisions around which tool to use may be based on criteria such as type of data, user preference, pedagogical purpose, or disciplinary practice. UNH provides a variety of software for student use in the classroom and support for academic software is provided by Academic Technology.

Some potential actions for supporting this recommendation include:

- Provide introductory tutorials, support outside the classroom, or online courses on the data analysis and statistical software commonly used in UNH classrooms.

- Work with instructors to better understand software needs and licensing options as related to how and why tools are used in the classroom. Departments can investigate options for more consistency around software-use decisions to help students focus on learning outcomes throughout the curriculum. 
Recommendation 4: Offer learning opportunities for instructors on teaching with data, student skills retention, and new research methodologies and data analysis and visualization practices.

Our findings suggest that participating in opportunities for learning new research methods, data analysis, and teaching practices becomes less common after graduate school. At UNH, the Center for Excellence and Innovation in Teaching \& Learning already provides resources for best practices in teaching. Data visualization is also a potential area for professional development, providing training for faculty to better present their own research results or learn about new, sometimes non-proprietary visualization tools, including those tools involving GIS and spatial data.

Some potential actions for supporting this recommendation include:

- Provide resources and workshops on teaching with data as well as strategies for promoting retention of conceptual learning and skills (e.g., math and statistics) from one course to another.

- Foster a community of practice for social science instructors who teach with data to promote networking, sharing of information, potential collaborations, and peer-to-peer learning.

Recommendation 5: Enhance library support for teaching with data and foster partnerships with campus stakeholders to explore recommendations 1-4.

Our findings suggest that the support needed by social science instructors cannot be addressed by a single campus stakeholder. For many of the recommendations above, the library's role is as partner. However, there are several areas for which the library can provide leadership or build on existing support for data-related activities (see Appendix $\mathrm{H}$ ).

Some potential actions for supporting this recommendation include:

- Develop and publicize research guides that list data resources for use in instruction or resources providing extracurricular support for math, software, or data concepts.

- Host datasets developed at UNH for teaching purposes in the UNH Scholars Repository, a repository service provided by the library.

- Investigate activities or services supporting teaching with data that are offered at other academic libraries and assess those for value, viability, and collaborative opportunities within UNH; for example, hosting software carpentry workshops.

- Work with library colleagues and others at the UNH Manchester campus to ensure appropriate support is available for both campuses.

- Consider other opportunities for collaborations or partnerships with campus stakeholders to extend and deepen communication at UNH about teaching with data; for example, host a social science (research methods) data instruction event. 


\section{Limitations}

There are some limitations to the methods used in this study. While the sample size for our local study was small and consisted of self-selecting participants, this is appropriate for an exploratory study. It is worth noting that "this study does not purport to be statistically representative nor are the recommendations meant to be prescriptive; rather, the report and its recommendations are intended to be suggestive of areas for further investigation" (Ithaka $\mathrm{S}+\mathrm{R}$ documentation). This study will be included in and complemented by a capstone report from Ithaka $S+R$ that will provide an aggregated analysis of interviews conducted at 20 institutions. This broader analysis will provide additional perspective and context for this local study and mitigates the limitation of its small size. The focus of this study was on undergraduate courses using quantitative data. Including graduate courses as well as the use of qualitative data would have provided a more holistic look at data literacy and teaching practices in social science courses and could be the topic of a follow-up investigation.

\section{Conclusion}

This exploratory study investigated the teaching practices of social science instructors who engage with undergraduate students using quantitative data in the classroom. The participants we interviewed teach both general and discipline-specific data concepts as academic, work, and life skills. Primary challenges discussed by the participants that students face in engaging with these topics are understanding math and statistical concepts, learning new software and computing skills, limited prior exposure to data, and lack of retention of content from earlier courses. Participants addressed challenges in several ways in order to lower barriers to learning, including finding, vetting, and cleaning data for their students to use. Participants could use additional support and new strategies to alleviate student challenges; our specific recommendations are discussed above.

Data literacy is an important set of competencies in part because of the quality and quantity of data students encounter; they need to have the ability to critically evaluate data, methods, and claims. This study directed attention to an area that had not previously been focused on at UNH and is an important first step toward creating greater awareness of the challenges of teaching with data and creating opportunities for building a community of practice for social science instructors grappling with these issues. Investigating questions about teaching undergraduate students to work with data was illuminating to the participants and the research team. The UNH Library offers existing research data services and is exploring new ways of supporting data literacy. UNH has opportunities to create additional supports for instructors and students that could improve student learning outcomes. Such efforts may require cross-college or cross-department coordination as well as administrative support. 


\section{References}

Alexander, B. (2021, March 19). Looking ahead to higher ed in fall 2021: Struggling towards normalcy. Brian Alexander. https://bryanalexander.org/future-of-education/lookingahead-to-higher-ed-in-fall-2021-struggling-towards-normalcy

Corbin, J., \& Strauss, A. (2014). Basics of qualitative research: Techniques and procedures for developing grounded theory. Sage Publications.

Cowell, P. (2021, February 15). COVID-19 has transformed education - Here are the 5 innovations we should keep. World Economic Forum. https://www.weforum.org/agenda/2021/02/covid-19-pandemic-higher-educationonline-resources-students-lecturers-learning-teaching/

Supiano, B. (2021, June 2). A pandemic silver lining? More people are talking about teaching. The Chronicle of Higher Education. https://www.chronicle.com/article/a-pandemicsilver-lining-more-people-are-talking-about-teaching 


\section{Appendices}

\section{Appendix A: Sample Selection}

This was a qualitative study that used one-on-one semi-structured interviews. The participants were purposively selected based on their pedagogical practices of using quantitative data in undergraduate social sciences courses. Anyone ( 21 years or older) who is paid by an academic department to teach undergraduates as the instructor of record, and who meets the study criteria, was eligible for recruitment in this study. This included tenured and tenure-track faculty, non-tenure track faculty, post-docs, graduate students, adjunct instructors, and staff.

Selection criteria were developed by Ithaka S+R for the "Teaching with Data in the Social Sciences" multi-institutional project. The following criteria (reprinted from Ithaka S+R project documentation) were used for selection:

- The participant has students work with quantitative data in a social sciences course. This includes analysis of physical specimens, landscapes, text, or images using computational methods, including GIS.

- The participant engages in teaching that encourages students to work more dynamically with data. This could include, but was not limited to:

- Gathering data through social science experiments, surveys, or other research

- Searching for appropriate datasets to address a particular research problem

○ Cleaning, analyzing, mining, visualizing, or otherwise manipulating data

- Drawing narratives or conclusions from data

- Learning to use specific tools, software, or programming languages to work with data

- Teaching about data (for example, its role in society) is not in scope for this project unless it also involves students working with data directly. Similarly, statistics and other prerequisite courses are not in scope unless they involve working with data in social science contexts.

- The participant uses data in their undergraduate teaching; graduate coursework is excluded. However, courses are sometimes cross-listed between undergraduate and graduate programs. These courses are in scope provided they have a substantial undergraduate enrollment (i.e., more than one or two students).

- Participants who teach courses listed or cross-listed in the following departments are examples considered in scope for the purposes of this study:
○ Anthropology
- Business Administration/
- Archaeology
Organizational Behavior
- Area Studies 
- Communication/ Communication Arts

- Cultural Studies (e.g., African American, Gender)

- Economics

- Education

- Environmental Science

- Geography

- Health Policy

o History

- Homeland Security/Terrorism Studies
- Human Development \&

Family Studies

- Law/Criminal Justice

- Linguistics

- Political Science

- Psychology

- Public Health/Public Administration/Social Work

- Sociology

- Recreation Management

- Urban Studies/Urban

Planning 


\section{Appendix B: Participant Recruitment}

\section{Recruitment Process}

Participants were purposively selected in order to capture a breadth of social sciences teaching activities that involve quantitative data at UNH and to include a variety of rank and variety of departmental affiliation. First, we identified a list of potential participants based on suggestions from stakeholders who we reached out to (such as department chairs and subject librarians), our own network on the UNH campuses, and course descriptions. Recruitment consisted of personalized email invitations sent directly to instructors/faculty at UNH Durham and Manchester campuses. The templates for the recruitment email and the follow-up email are included below.

Recruitment emails were developed by Ithaka $S+R$ for the "Teaching with Data in the Social Sciences" multi-institutional project and reprinted here with permission.

\section{Recruitment Email}

Subject: UNH's study on teaching with data in the social sciences

Dear [first name of instructor],

Faculty from the UNH Library are conducting a study on the practices of social science instructors in order to improve support services for the instructors' work. We are interviewing instructors whose undergraduate students engage with quantitative data, such as by conducting research using quantitative methods, analyzing or visualizing datasets, or learning to use specific tools or software to work with data. Would you be willing to participate in a onehour interview to share your unique experiences and perspectives?

Our local UNH study is part of a suite of parallel studies at 23 other institutions of higher education in the US, coordinated by Ithaka $\mathrm{S}+\mathrm{R}$, a not-for-profit research and consulting service. The information gathered at UNH will also be included in a landmark capstone report by lthaka $\mathrm{S}+\mathrm{R}$ and will be essential for UNH to further understand how the support needs of social science instructors are evolving more broadly.

If you have any questions about the study, please don't hesitate to reach out. Thank you so much for your consideration.

Sincerely,

[project team]

\section{Follow-up Recruitment Email}

Subject: Re: UNH's study on teaching with data in the social sciences

Dear [first name of instructor], 
Thank you for expressing your interest in participating in this study. We would love to set up a time to interview you [via Zoom] at your convenience. Please advise me of your availability in [time frame].

Before the interview begins, we will ask you to read an informed consent form in order to ensure that you understand the study and are willing to participate in it. I am attaching the form to this email. We will review it at the beginning of our interview as well.

Sincerely,

[project team] 


\section{Appendix C: Informed Consent}

\section{Consent process}

We recorded informed consent from participants verbally at the beginning of each interview. For participants who responded to our recruitment email, we replied with the informed consent form as a PDF attachment so they could review the document in advance. At the interview, prior to recording, we reviewed the purpose of the study and the content of the informed consent with participants. Once the recording started, we asked if the participant had any questions and confirmed whether they consented to participate. This consent was included in the transcription for each interview. Below is the IRB-approved Informed Consent Form used for this study (IRB \#: 8353).

\section{Consent form for participation in a research study}

\section{RESEARCHER AND TITLE OF STUDY}

Our names are Louise Buckley, Patti Condon, and Eleta Exline and we are library faculty at the University of New Hampshire. The title of our research project is "Teaching with Data in the Social Sciences."

\section{WHAT IS THE PURPOSE OF THIS FORM?}

This consent form describes our research study and helps you to decide if you want to participate. It provides important information about what you will be asked to do in the study, about the risks and benefits of participating in the study, and about your rights as a research participant. You should:

- Read the information in this document carefully and ask me or the other investigators any questions, particularly if you do not understand something.

- Not agree to participate until all your questions have been answered, or until you are sure that you want to.

- Understand that your participation in this study involves you answering questions about how you use data in your instruction to engage undergraduates in the social sciences. The interview will last about 60 minutes, be recorded, and take place remotely via Zoom or telephone, or in person once the University allows it.

- Understand that the potential risks of participating in this study are minimal but include possible breaches of confidentiality resulting in your identity being discoverable. The researchers will take steps, outlined below, to minimize this risk.

WHAT IS THE PURPOSE OF THIS STUDY?

This study examines social science instructors' practices in teaching undergraduate students to work with quantitative data. The researchers are interested in exploring the ways in which instructors teach undergraduates through hands-on use of data and the kinds of resources and 
services that instructors at the University of New Hampshire need to be successful in their work.

The study at UNH is connected to a suite of parallel studies being developed locally at 23 other higher education institutions. Ithaka $\mathrm{S}+\mathrm{R}$, a not-for-profit research and consulting organization that helps the academic, cultural, and publishing communities, has been engaged by multiple institutions to coordinate this parallel effort and to provide guidance on research methodology and data analysis. The results of the research at UNH will be compiled with the results of the other institutions to produce an aggregated report published by Ithaka S+R.

We anticipate interviewing 15 people at UNH who use quantitative data in their undergraduate instruction in social sciences courses.

Participants must be at least 21 years old to participate in the study. Participants must be the instructor of record of an undergraduate social science course or a cross-listed social science course with significant undergraduate enrollment. Participants must be engaged in teaching that encourages students to work more dynamically with quantitative data.

\section{WHAT DOES YOUR PARTICIPATION IN THIS STUDY INVOLVE?}

Your participation in the study involves a 60-minute, recorded interview about teaching practices. The interview will take place over Zoom or telephone, or in person once the University allows it. During the interviews you will be asked questions on topics related to how you use data for teaching undergraduates in the social sciences. Areas the interview explores include how participants get access to data, how students work with the data, and what other support instructors use in the classroom for helping students work with data.

\section{WHAT ARE THE POSSIBLE RISKS OF PARTICIPATING IN THIS STUDY?}

The risks associated with participating in this study are minimal. The main risk is breach of confidentiality. Because the number of participants is small and the study location easy to deduce, there is a minimal risk of identification of the participants.

\section{WHAT ARE THE POSSIBLE BENEFITS OF PARTICIPATING IN THIS STUDY?}

There are no direct benefits to you. You may experience benefits in the form of increased insight and awareness into your own teaching practices and needs. The anticipated benefits of the knowledge gained via the study are to understand instructors' support needs for teaching with data and to identify library and university support services to assist instructors using data in the classroom.

WILL YOU RECEIVE ANY COMPENSATION FOR PARTICIPATING IN THIS STUDY?

You will not be offered compensation for participating in the study.

\section{DO YOU HAVE TO TAKE PART IN THIS STUDY?}

Taking part in this study is completely voluntary. You may choose not to take part at all. If you agree to participate, you may refuse to answer any question. If you decide not to participate, you will not be penalized or lose any benefits for which you would otherwise qualify. 
CAN YOU WITHDRAW FROM THIS STUDY?

If you agree to participate in this study and you then change your mind, you may stop participating at any time. If you decide to stop participating at any time, you will not be penalized or lose any benefits for which you would otherwise qualify. Any data collected as part of your participation will remain part of the study records. If you withdraw from the study, you may request that any data collected as part of your participation not be quoted directly.

\section{HOW WILL THE CONFIDENTIALITY OF YOUR RECORDS BE PROTECTED?}

We plan to maintain the confidentiality of all data and records associated with your participation in this research.

There are, however, rare instances when we may be required to share individually identifiable information with the following:

- Officials at the University of New Hampshire, or

- Regulatory and oversight government agencies.

Further, any communication via the internet poses minimal risk of a breach of confidentiality.

To help protect the confidentiality of your information, we will

- Store all study materials in secure, password-protected Box folders.

- Save signed informed consent forms (if available) in a separate Box folder and not maintain a key that links the signed forms to de-identified transcripts.

- Store recordings temporarily on Box and delete them upon completion of typed transcripts.

- De-identify typed transcripts and associated metadata promptly and prior to analysis, long-term storage, or sharing with Ithaka S+R or other collaborators.

- Not attribute any quotes in a way that would allow them to be easily identifiable.

- Not provide detailed individual-level context for any comments made.

Identifiable information may be shared with an online transcription service. The service we will use has a secure platform and confidentiality assurances in place.

Louise Buckley, Patti Condon, and Eleta Exline will have access to the recorded interviews, consent forms, and typed interview transcripts. Once de-identified, the interview transcripts may be used for future studies or shared with future research collaborators.

The de-identified transcripts will be shared with the research team at Ithaka $S+R$, however they are not authorized to share the de-identified transcripts with other researchers. Ithaka $S+R$ will have no access to the research participants, their personal information, signed consent form (if applicable), or the recordings. Ithaka $S+R$ will only have access to de-identified interview transcripts. They may use the de-identified transcripts for other reports. 
We will report the results using pseudonyms. We will not attribute any quotations in a way that would allow them to be easily identifiable or provide detailed individual-level context for any comments made. The results may be used in publicly available reports, presentations, and publications.

WHOM TO CONTACT IF YOU HAVE QUESTIONS ABOUT THIS STUDY

If you have any questions pertaining to the research, you can contact Patti Condon (patricia.condon@unh.edu) to discuss them.

If you have questions about your rights as a research subject, you can contact Melissa McGee in UNH Research Integrity Services, 603/862-2005 or melissa.mcgee@unh.edu to discuss them. 
Appendix D: Interview Guide

\section{Interview process}

One member of the research team was responsible for sending recruitment emails and scheduling interviews. Interviews were conducted during the fall 2020 semester. All UNH research team members were trained on the consent process and interview instrument to ensure consistency across interviews. Recorded interviews were conducted one-on-one via Zoom, an online video conferencing platform. Once recorded, the video file was deleted and the audio file was saved to Box, a UNH-approved cloud storage.

The audio file was shared with the transcription service via a private Box folder. The transcription service provided initial de-identification of the interview transcript and two members of the research team reviewed each transcript to complete de-identification of the data. Once transcriptions were received and reviewed for accuracy, the transcription service lost access to the audio files. Audio files were permanently deleted once data analysis was complete, leaving only de-identified transcripts as part of the study records.

At the close of each interview, we thanked the interviewee for participating, encouraged them to reach out if they had any follow-up comments or questions, and reviewed the timeline for completion of the project. We informed them that we would send them a link to the final report when it was published and provide a presentation to stakeholders once the Ithaka $S+R$ aggregate report was published.

\section{Interview instrument}

The interview instrument was developed by Ithaka S+R for the "Teaching with Data in the Social Sciences" multi-institutional project and is reprinted here with permission.

\section{Teaching with Data in the Social Sciences: Interview Guide}

Note regarding COVID-19 disruption I want to start by acknowledging that teaching and learning has been significantly disrupted in the past year due to the coronavirus pandemic. For any of the questions I'm about to ask, please feel free to answer with reference to your normal teaching practices, your teaching practices as adapted for the crisis situation, or both.

\section{Background}

Briefly describe your experience teaching undergraduates.

1. How does your teaching relate to your current or past research?

2. In which of the courses that you teach do students work with data?

\section{Getting Data}

In your course(s), do your students collect or generate datasets, search for and select preexisting datasets to work with, or work with datasets that you provide to them?

If students collect or generate datasets themselves Describe the process students go through to collect or generate datasets in your course(s). 
1. Do you face any challenges relating to students' abilities to find or create datasets? If students search for pre-existing datasets themselves Describe the process students go through to locate and select datasets.

2. Do you provide instruction to students in how to find and/or select appropriate datasets to work with?

3. Do you face any challenges relating to students' abilities to find and/or select appropriate datasets?

If students work with datasets the instructor provides Describe the process students go through to access the datasets you provide. Examples: link through LMS, instructions for downloading from database

4. How do you find and obtain datasets to use in teaching?

5. Do you face any challenges in finding or obtaining datasets for teaching? Working with Data

How do students manipulate, analyze, or interpret data in your course(s)?

1. What tools or software do your students use? Examples: Excel, online platforms, analysis/visualization/statistics software

2. What prior knowledge of tools or software do you expect students to enter your class with, and what do you teach them explicitly?

3. To what extent are the tools or software students use to work with data pedagogically important?

4. Do you face any challenges relating to students' abilities to work with data?

How do the ways in which you teach with data relate to goals for student learning in your discipline?

5. Do you teach your students to think critically about the sources and uses of data they encounter in everyday life?

6. Do you teach your students specific data skills that will prepare them for future careers?

7. Have you observed any policies or cultural changes at your institution that influence the ways in which you teach with data?

Do instructors in your field face any ethical challenges in teaching with data?

8. To what extent are these challenges pedagogically important to you?

\section{Training and Support}

In your course(s), does anyone other than you provide instruction or support for your students in obtaining or working with data? Examples: co-instructor, librarian, teaching assistant, drop-in sessions 
1. How does their instruction or support relate to the rest of the course?

2. Do you communicate with them about the instruction or support they are providing? If so, how?

To your knowledge, are there any ways in which your students are learning to work with data outside their formal coursework? Examples: online tutorials, internships, peers

3. Do you expect or encourage this kind of extracurricular learning? Why or why not? Have you received training in teaching with data other than your graduate degree? Examples: workshops, technical support, help from peers

4. What factors have influenced your decision to receive/not to receive training or assistance?

5. Do you use any datasets, assignment plans, syllabi, or other instructional resources that you received from others? Do you make your own resources available to others?

Considering evolving trends in your field, what types of training or assistance would be most beneficial to instructors in teaching with data?

Wrapping Up

Is there anything else from your experiences or perspectives as an instructor, or on the topic of teaching with data more broadly, that I should know? 


\section{Appendix E: Codebook}

\section{Coding process}

We employed the coding process that was recommended by Ithaka S+R. We used NVivo, a qualitative analysis software, for coding and analysis of the data.

1. Using our own instance of the software, each research team member uploaded deidentified interview transcripts to NVivo.

2. All three team members conducted open coding on the same three interview transcripts to identify emergent themes/codes in the data.

3. The team discussed and compared the codes from each team member and selected several core themes/codes that emerged from the open coding.

4. Together, we determined a final set of seven codes to use for analyzing the interviews.

5. We assigned each member 2-3 codes from the final set. Using those assigned codes, we analyzed all of the interview transcripts.

6. Once coding was complete, the team identified two overarching themes that emerged from the final set of codes. The teaching with data for data and scientific literacies theme developed from the codes learning objectives and challenges understanding data. The teaching with data for statistical, data, and tools skill building theme developed from the codes learning objectives, challenges understanding data, student prior learning, locating and providing data, and support outside the classroom.

De-identified interview transcripts and de-identified metadata (participant ID, rank, and department) were shared with Ithaka S+R for them to conduct an aggregated analysis.

\section{Codebook}

We identified seven codes from our open coding to use as our final set for focused coding. These are defined below with associated subcodes.

1. Learning objectives. Comments and reflections about learning objectives instructors have defined as desired outcomes for their students within courses.

Subcode: Concepts - analysis and application

Description: Comments and reflections about analysis and application of data as course learning objectives
Subcode: Concepts - ethics

Description: Comments and reflections about research ethics as course learning objectives 
Subcode: Concepts - measurement and variables

Description: Comments and reflections about measurement and variable concepts as course learning objectives

Subcode: Concepts - research methods Description: Comments and reflections about research methods, including specific methodologies and broad concepts, as course learning objectives

Subcode: Concepts - statistics Description: Comments and reflections about statistics concepts as course learning objectives

Subcode: Concepts - visualization

Description: Comments and reflections about data visualization and interpretation of visuals as course learning objectives
Subcode: Information and data literacy (life skills)

Description: Comments and reflections about information and data literacy skills as course learning objectives

Subcode: Tools

Description: Comments and reflections about working with software, technology, and other tools as course learning objectives

Subcode: Workplace skills

Description: Comments and reflections about developing workplace skills or transferable skills as course learning objectives

2. Challenges understanding data. Comments and reflections about challenges students experience in understanding data concepts and working with data.

Subcode: Challenges - analysis and application Description: Comments and reflections about how students have difficulty with written analysis and application of data

Subcode: Challenges - ethics

Description: Comments and reflections about how students have difficulty grasping research ethics, including plagiarism

Subcode: Challenges - measurement and variables

Description: Comments and reflections about how students have difficulty understanding variables and how they are measured
Subcode: Challenges - research methods Description: Comments and reflections about how students have difficulty with research methods, including specific methodologies and broad concepts

Subcode: Challenges - tools Description: Comments and reflections about how difficulty with software, technology, and other tools inhibit student understand of data

Subcode: Challenges - statistics Description: Comments and reflections about how students have difficulty grasping or retaining statistical concepts 
Subcode: Challenges - visualization Description: Comments and reflections about how students have difficulty understanding how to visualize data or interpret visualizations
Subcode: Student motivations and experiences

Description: Comments and reflections about how student motivations or limited experience contribute to difficulty understanding data

3. Student prior learning. Comments and reflections about expected preparation at the high school level or college level prior to the data course, student skills or viewpoints brought to the data course, perceived student anxiety about math or science, perceived student abilities with mathematical concepts or skills, student motivation, and perceived student challenges with basic software, technical familiarity, and access.

Subcode: College preparation

Description: Comments and reflections about expected preparation at the college level prior to the data course

Subcode: Foundational skills

Description: Comments and reflections about skills or viewpoints that students bring to the data course

Subcode: High school preparation Description: Comments and reflections about expected preparation at the high school level

Subcode: Math anxiety Description: Comments and reflections about students' perceived math or science anxiety as it relates to data course
Subcode: Math concepts and skills Description: Comments and reflections about students' perceived abilities with mathematical concepts or skills as it relates to data course

Subcode: Student motivation Description: Comments and reflections about students' perceived motivations or feeling about the data course

Subcode: Technology - access Description: Comments and reflections about students' perceived or reported problems with accessing required software, accessing the campus network, or computer issues

Subcode: Technology - software Description: Comments and reflections about challenges with use of software

4. Locating and providing data for use. Comments and reflections about finding datasets for use in teaching, qualities of data that instructors look for, common sources for usable data, and challenges teaching with data.

Subcode: Challenges teaching with data Description: Comments and reflections about challenges related to finding and preparing datasets for teaching
Subcode: Finding data

Description: Comments and reflections about finding and preparing data to use in the classroom 
Subcode: Reasons for providing data Description: Comments and reflections about rationale for providing datasets to students rather than having students locate/collect data
Subcode: Students collect/find data Description: Comments and reflections about when students find or collect their own data for use in the classroom

Subcode: Vetted datasets

Description: Comments and reflections about vetting datasets for students to select from

5. Support outside the classroom (for both students and instructors). Comments and reflections about where students go for support regarding data-related questions or needs outside the classroom. Comments and reflections about professional development for instructors around teaching with data and learning new methodologies and tools.

Subcode: Professional development for instructors

Description: Comments and reflections on professional development for instructors in the area of teaching with data and learning new methodologies and tools
Subcode: Support for students Description: Comments and reflections about where students may go for support (re: data) outside the classroom

Subcode: Teaching assistants Description: Comments and reflections about lab instructors, teaching assistants, graduate assistants who provide support for the instructor and students in the class

6. Useful training or assistance. Comments and reflections about possible changes to curriculum or courses or suggestions as to other types of support or training for students and/or instructors working with data in the classroom.

Subcode: Wants - curriculum Description: Comments and reflections about desired changes to the curriculum or courses

Subcode: Wants - data lab or place Description Comments and reflections about a specialized location for teaching data

Subcode: Wants - data-related support Description: Comments and reflections about activities or resources that would help with getting, using, or visualizing data
Subcode: Wants - software Description: Comments and reflections about desired software

Subcode: Wants - support \& collaboration

Description: Comments and reflections about desired enhancements to general support and collaboration for students and faculty 
7. COVID-19 impacts. Comments and reflections about impacts to teaching and learning (generally online) during the COVID-19 pandemic. 
Appendix F: Data Management Plan

The data management plan for this study is available in the UNH Scholars Repository.

Condon, P. B., Exline, E., \& Buckley, L. (March 2021). Teaching Quantitative Data in the Social Sciences at the University of New Hampshire: Data Management Plan.

https://scholars.unh.edu/faculty pubs/1008 


\section{Appendix G: Additional Comments on Useful Training and Assistance}

One of the closing questions from the interview guide was "Considering evolving trends in your field, what types of training or assistance would be most beneficial to instructors in teaching with data?" This question elicited a variety of responses from our participants that were considered when developing recommendations. We have included more details here from responses to that question because they may be useful for stakeholders interested in operationalizing the recommendations in this report.

\section{Curriculum and training}

Several participants expressed a desire for a more uniform data literacy experience for students around topics related to working with data (e.g., data extraction and manipulation) and statistics (e.g., foundational descriptive statistics and statistical reasoning).

There was interest in providing more depth and experience for students working with data throughout the research lifecycle to improve exposure to data collection, analysis software, and data visualization.

While several comments spoke to helping students build greater data expertise within their discipline, another desired direction was a "stronger core curriculum course in understanding data from a consumer perspective," one that would inform students how "quantitative information shapes [their] world."

\section{Place}

Some participants saw value in facilities such as computer labs for instruction, where there would be uniformity and ready availability of software that was already installed, or a data lab where students can go for support, especially for tutoring services that are geared toward social sciences data applications rather than math tutoring.

\section{Software}

Participants noted a need for university-level licenses for statistical analysis software to be reviewed to ensure that the software versions are sufficient for classroom and research use. In addition, licenses are sometimes only available for PC at a time when most students are using Macs.

While this study's scope involved only quantitative data, participants occasionally spoke about qualitative data. As compared with that for quantitative research, the university's support for qualitative research software was seen as limited in terms of affordable access to this type of software. One participant framed it as "almost an inequity now" for qualitative researchers who are "carrying a load that the quantitative researchers don't have to support." 


\section{Resources}

To make anonymized, cleaned, vetted, and interesting data more easily available to students, one participant brought up the idea of creating a collaboratively generated longitudinal dataset about UNH students for use by UNH students in the classroom.

Another participant was considering creating their own workbook with more up-to-date data sets than what was available through the usual textbook publisher.

There was also interest in more opportunities for sharing of data and information with colleagues and more encouragement of sharing, especially with students; for example, using a data set from a colleague within a department who could then talk with students about the research (design) and the data (results, analysis). Such an activity was seen as engaging for students and as providing more exposure to work being done in the department. Sharing of resources for teaching with data such as "specific kinds of activities that support certain kinds of analyses" or "certain approaches to data" was mentioned in the context of assisting people new to teaching research methods but could be more generally valuable as well. 
Appendix H: Library Support for Data-Related Activities at UNH

UNH Library has existing support for data-related activities. Library support for data services includes:

- Funding and administering UNH's membership in ICPSR (Inter-university Consortium for Political and Social Research)

- Research data management support, including

○ Developing and reviewing data management plans

- Advising on research data repositories

○ Data Management Toolkit @ UNH guide

- Other online guides

- ICPRS \& Other Social Science Data Sources guide

- Introduction to Excel and Spreadsheets guide with information on data cleaning, data analysis, and data visualization

- UNH Scholars Repository, including

- Data Catalog - an inventory of data sets that UNH researchers have deposited in external repositories for long-term access and preservation

○ Digital Object Identifier (DOI) creation

- Student scholarship

- Geospatial Services Center 